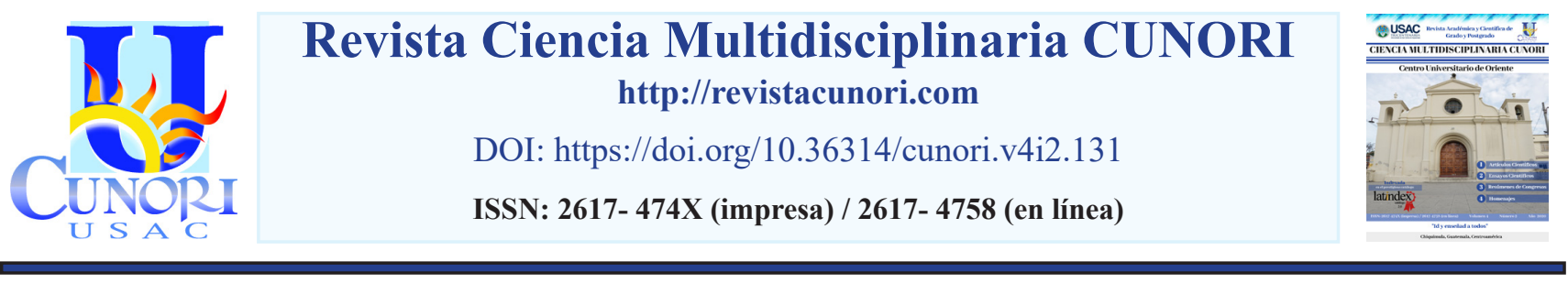

Referencia del artículo

García-González, E. L. (2020). La Independencia Judicial en Guatemala en la Elección de Magistrados de Corte Suprema de Justicia, Corte de Apelaciones y de Tribunales de Igual Categoría. Revista Ciencia Multidisciplinaria Cunori, 4(2), 83-88. https://doi.org/10.36314/cunori.v4i2.131

\title{
La Independencia Judicial en Guatemala en la Elección de Magistrados de Corte Suprema de Justicia, Corte de Apelaciones y de Tribunales de Igual Categoría
}

\section{Judicial Independence in Guatemala in the Election of Magistrates of the Supreme Court of Justice, Court of Appeals and Courts of the Same Category}

\author{
Emma Lucrecia García González \\ Centro Universitario de Oriente, Universidad de San Carlos de Guatemala \\ https://orcid.org/0000-0002-1144-0162 \\ Recibido: 18 de septiembre de 2020 / Revisado: 19 de septiembre de 2020 / Aceptado: 14 de octubre de 2020
}

Disponible en internet el 30 de octubre de 2020

*Autor para correspondencia.

Correo electrónico: lic.emmalucreciagarcia@gmail.com

Resumen

\begin{abstract}
Q 1 enfoque sustancial de este artículo radica en establecer el proceso de elección de Magistrados de la Corte Suprema de JusEticia, Cortes de Apelaciones y de Tribunales de igual categoría, por medio de las Comisiones de Postulación y el Congreso de la República de Guatemala, en donde se pone de manifiesto la Independencia Judicial, en cuanto a su ejercicio, por medio de un estudio jurisprudencial, jurídico y de realidad nacional, sobre el tema: "La Independencia Judicial en Guatemala en la elección de Magistrados de Corte Suprema de Justicia, Corte de Apelaciones y de Tribunales de Igual Categoría”. El problema planteado es ¿Existen factores que interfieren en la Independencia Judicial en la elección de Magistrados de Corte Suprema de Justicia, Corte de Apelaciones y de Tribunales de igual categoría? La hipótesis de trabajo es "Existen factores políticos que limitan e inciden en el ejercicio de la Independencia Judicial en Guatemala en la elección de Magistrados, en virtud que no se privilegia la capacidad, experiencia e idoneidad del operador de justicia en su Carrera Judicial". Este estudio se realiza desde la perspectiva de la realidad nacional, específicamente en la elección de Cortes 2019-2024, recurriendo a procedimientos que permiten alcanzar los objetivos planteados, utilizando técnicas bibliográficas para recopilar escritos por autores nacionales e internacionales, y así conocer los factores que limitan la Independencia Judicial, para verificar las falencias del procedimiento desde las Comisiones de Postulación hasta la elección realizada por el Congreso de la República de Guatemala.
\end{abstract}

Palabras clave: independencia judicial, elección de magistrados, factores políticos

\footnotetext{
Abstract

$\mathrm{T}$ he substantial focus of this article lies in establishing the election process for Magistrates of the Supreme Court of Justice, Courts of Appeals and Courts of the same category, through the Nomination Commissions and the Congress of the Republic of Guatemala, where Judicial Independence, in terms of its exercise, is revealed through a jurisprudential, legal and national reality study on the subject: Judicial Independence in Guatemala in the election of Supreme Court Justices, Court of Appeals and Courts of the Same Category. The problem raised is: Are there factors that interfere with Judicial Independence in the election of Magistrates of the Supreme Court of Justice, the Court of Appeals and Courts of the same category? The working hypothesis is: "There are political factors that limit and influence the exercise of Judicial Independence in Guatemala in the election of Magistrates, since the capacity, experience and suitability of the justice operator in his Judicial Career are not privileged". This study is carried out from
} 
the perspective of national reality, specifically in the election of Cortes 2019-2024, using procedures that allow achieving the stated objectives, using bibliographic techniques to compile writings by national and international authors, and thus know the factors that limit Judicial Independence, to verify the shortcomings of the procedure from the Nomination Commissions to the election made by the Congress of the Republic of Guatemala.

Keywords: judicial independence, election of magistrates, political factors

\section{Introducción}

La presente investigación tiene la finalidad de establecer el proceso de elección de Magistrados de la Corte Suprema de Justicia, Cortes de Apelaciones y de Tribunales de igual categoría, por medio de las Comisiones de Postulación y el Congreso de la República de Guatemala, las cuales han sido duramente cuestionadas en los últimos años y en donde se pone de manifiesto la independencia judicial, en cuanto a su ejercicio, toda vez que se ve limitada, y en muchas ocasiones los operadores de justicia es decir los Magistrados, no pueden ejercerla, en virtud de los compromisos asumidos al momento de su elección. El autor Malem Seña establece: "en países como España, con una democracia constitucional, no conviene olvidar que el juez también es un funcionario público sujeto a normas específicas que le son aplicables debido únicamente a su estatus. Los derechos de los jueces y el nivel de su disfrute dependen por completo, entonces, del sistema jurídico aplicable al juez y del entramado institucional que es del todo contingente" (2017. Pág. 47).

La Comisión Internacional de Juristas, en su publicación intitulada La Independencia Judicial en Guatemala, señala que "Los Jueces resolverán los asuntos de que conozcan con imparcialidad, basándose en los hechos y en consonancia con el derecho, sin restricción alguna y sin influencias, alicientes, presiones, amenazas o intromisiones indebidas, sean directas o indirectas, de cualquiera sector o por cualquier motivo" (2016. Pág. 61). Ambas definiciones se conjugan con lo establecido por el Estatuto de Juez Iberoamericano que dispone que, en el ejercicio de la jurisdicción, los jueces no se encuentran sometidos a autoridades judiciales superiores, sin perjuicio de la facultad de éstas de revisar las decisiones jurisdiccionales a través de los recursos legalmente establecidos, y de la fuerza que cada ordenamiento nacional atribuya a la jurisprudencia y a los precedentes emanados de la Cortes Supremas y Tribunales Supremos.

La Honorable Corte de Constitucionalidad el doce de septiembre de dos mil diecinueve dentro del expediente 2136-2018 se pronunció en cuanto a la solicitud de Opinión Consultiva, promovida por el Magistrado José Antonio Pineda Barales, en calidad de Presidente de la Corte Suprema de Justicia y del Organismo Judicial en donde resolvió el cuestionamiento ¿debe la Corte Suprema de Justicia nombrar a los jueces, promover y ascender a los mismos?, de la siguiente manera: en algunos supuestos conllevan asumir determinaciones sobre asuntos tales como sustituciones provisionales, traslados o permutas; pero es importante resaltar que se trata de movimientos horizontales, siguiendo la terminología propuesta antes, porque en ningún caso implican decidir si los ciudadanos adquieren la investidura de jueces o si deben perderla por algún motivo justificado, ni conceder ascensos a los funcionarios mencionados, según la definición regulada en la Ley de la Carrera Judicial. 
En tal virtud, la Corte concluye que de acuerdo con la interpretación integral de la preceptiva constitucional y legal vigente sobre la materia, la Corte Suprema de Justicia es la única autoridad que posee la responsabilidad de nombrar a los jueces, en cuanto conferirles esa calidad a los ciudadanos, y de ascenderlos, en cuanto adjudicarles un cargo de competencia diferente y superior por razón de categoría o instancia, en el plano de las judicaturas de paz y de primera instancia". Las reformas a la Ley de la Carrera Judicial Decreto 32-2016 del Congreso de la República de Guatemala, les otorgo importantes funciones administrativas a la Carrera judicial, como lo es que los Jueces y Magistrados con un desempeño satisfactorio tienen derecho a ser elegidos "preferentemente" en el proceso de elección de magistrados de las Salas de Apelaciones y la Corte Suprema de Justicia. El Artículo 76 indica que el Consejo de la Carrera Judicial debe enviar a las comisiones de postulación encargadas de dicho proceso una nómina con los expedientes de los Jueces y Magistrados interesados en participar en el proceso. La nómina se debe elaborar con base en un proceso previo de evaluación que tome en consideración los años de experiencia en el ejercicio de la judicatura, la especialización y el desempeño profesional satisfactorio o sobresaliente de los Jueces y Magistrados. La Ley de la Carrera Judicial establece que los miembros de la Carrera Judicial con un destacado desempeño deberían ser elegidos "preferentemente" para ocupar las Salas de Apelaciones y la Corte Suprema de Justicia. Por ello es importante que las evaluaciones de Jueces y Magistrados se realicen con instrumentos y técnicas objetivamente diseñadas, certificadas y de conformidad con estándares nacionales e internacionales.

\section{Materiales y métodos}

En la investigación se utilizó el método analítico, método sintético, método inductivo y método deductivo. Se utilizaron, además, las técnicas de investigación bibliográfica, jurídica, documental, de campo y de observación.

Las principales fuentes bibliográficas de consulta utilizadas llevaron a conocer las opiniones de teóricos expertos en el tema de la independencia judicial, como Malem Seña, Comisión Internacional de Juristas, Estatuto Iberoamericano, entre otros, asimismo, los distintos fallos emitidos por la Honorable Corte de Constitucionalidad. La investigación se realizó desde la perspectiva del positivismo jurídico.

\section{Resultados}

Es oportuno concretizar los alcances fundamentales que proporcionan primacía al presente artículo. Uno de los principios internacionales sobre la Independencia Judicial es el de Independencia, este principio se refiere no solamente que el poder judicial debe tener independencia como institución, sino que además los Jueces deben gozar individualmente de independencia dentro del sistema judicial y en relación con otras instituciones. Asimismo dicha independencia aun cuando en un caso específico el Juez pueda actuar de manera independiente, un Estado violaría sus obligaciones internacionales si el poder judicial no fuera un poder independiente, lo que significa que la independencia se refiere tanto a un Juez individual como también al poder judicial en su conjunto. Según la Comisión Internacional de Juristas, la Comisión Interamericana de Derechos Humanos, se ha manifestado en los siguientes términos: "el requisito de independencia requiere que los tribunales sean autónomos de otras ramas del gobierno, estén libres de influencias, amenazas o interferencias de cualquier origen o por cualquier razón y cuenten con 
otras características necesarias para garantizar el cumplimiento apropiado e independiente de las funciones judiciales, incluidas la estabilidad de un cargo y la capacitación profesional adecuada”.

La Imparcialidad individual significa que los jueces no pueden decidir casos de acuerdo con sus preferencias personales, sino únicamente de acuerdo con el derecho. "Los jueces resolverán los asuntos de que conozcan con imparcialidad, basándose en los hechos y en consonancia con el derecho, sin restricción alguna y sin influencias, alicientes, presiones, amenazas o intromisiones indebidas, sean directas o indirectas, de cualquiera sector o por cualquier motivo".

El Artículo 203 de la Constitución Política de la República de Guatemala establece "Los magistrados y jueces son independientes en el ejercicio de sus funciones y únicamente están sujetos a la Constitución de la República y a las leyes. A quienes atentaren contra la independencia del Organismo Judicial, además de imponérseles las penas fijadas por el Código Penal, se les inhabilitará para ejercer cualquier cargo público". La Corte Interamericana de Derechos Humanos, ha señalado que "uno de los objetivos principales que tiene la separación de los poderes públicos, es la garantía de la independencia de los jueces". También, el Tribunal Europeo de Derechos Humanos ha reafirmado que el respeto al principio de división de poderes es un principio esencial de una democracia que no puede ser puesto en duda (Sentencia del 13 de febrero de 2003, Caso Chevrol c. Francia, Serie 2003-III, párr. 74).

El Artículo 203 de la Constitución Política de la República de Guatemala establece "la función jurisdiccional se ejerce, con exclusividad absoluta, por la Corte Suprema de Justicia y por los demás tribunales que la ley establezca. Ninguna otra autoridad podrá intervenir en la administración de justicia”. Las Comisiones de Postulación están conformadas por altos funcionarios públicos, autoridades universitarias públicas y privadas, representantes de los colegios profesionales, con el propósito de regular y establecer mecanismos y procedimientos en cuanto a la elección de las nóminas de candidatos de Magistrados de la Corte Suprema de Justicia, de la Corte de Apelaciones y de otros Tribunales de igual categoría, deben evidenciar el cumplimiento del Artículo 76 de la Ley de la Carrera Judicial.

Pero lo que se evidenció es que dichas Comisiones de Postulación han respondido a intereses personales, en los cuales no se pondera la prevalencia de la Carrera Judicial, en la cual pueda ascender de Juez de Paz, a Juez de Primera Instancia, a Magistrado de las Cortes de Apelaciones y por último a Magistrados de la Corte Suprema de Justicia, tal y como lo preceptúa el Artículo 14 de la Ley de la Carrera Judicial, en la cual establece la clasificación de la carrera judicial, así: a) Magistrados de la Corte Suprema de Justicia; b) Magistrados de la Corte de Apelaciones y otros tribunales colegiados de igual categoría; c) Jueces de primera instancia; y, d) Jueces de paz, sin embargo a lo largo de la presente investigación se estableció que existe una gran división en la cual la carrera judicial únicamente está constituida por dos sectores, Jueces de Paz y Jueces de Primera Instancia, los cuales ingresan a la misma por medio de un sistema de oposición, en la cual para ingresar deben someterse a auditoria social de toda la población, sustentar exámenes psicométricos, jurídicos y entrevistas, posteriormente acudir al menos ocho meses a la Escuela de Estudios Judiciales, para ser capacitados en todas las ramas del derechos, caso contrario ocurre con la elección de Magistrados de Cortes de Apelaciones, Magistrados de Corte Suprema de Jus- 
ticia y de Tribunales de igual categoría, en la cual el sistema de elección por medio de las Comisiones de Postulación, no responden al interés de que exista una verdadera independencia judicial, sino que al contrario vemos con suma preocupación cómo ha tenido que intervenir la Corte de Constitucionalidad y Ministerio Público, para evidenciar que muchos comisionados responden a intereses particulares, en las cuales el interés es poder poner a abogados de su conveniencia para que en futuras oportunidades revoquen lo resuelto por Jueces de Primera Instancia en apelación. Todos estos factores políticos son evidentes en los cuales la Corte de Constitucionalidad ordena que se aparten de los mismos y realicen la elección conforme a la honorabilidad, capacidad e idoneidad. Asimismo vemos con preocupación cómo se quebrantan los plazos Constitucionales, en los cuales el sistema de elección cada cinco años es cooptado por grupos de poder, limitando con esto el libre ejercicio de la independencia judicial.

\section{Discusión}

Existen factores políticos al libre ejercicio de la independencia judicial, siendo uno de ellos la forma de elección de Magistrados de la Corte Suprema de Justicia, Magistrados de las Cortes de Apelaciones y de Tribunales Colegiados de igual categoría, por parte del Congreso de la República de Guatemala, los cuales han respondido a intereses personales, en donde no se pondera la prevalencia de la Carrera Judicial y los aspectos de honorabilidad, capacidad e idoneidad, siendo necesario que los órganos con iniciativa de Ley viabilicen el proceso de Reforma Constitucional que permita establecer un proceso de elección adecuado en el cual se garantice la elección de profesionales con Carrera Judicial y que dichas reformas sean congruentes con la Ley de la Carrera Judicial la cual es Constitucional, y que por ende prevalezca el artículo 77 de la citada ley, en la cual se de preferencia a los miembros de la Carrera Judicial, para integrar la nómina de candidatos a ocupar las Cortes de Apelaciones, Cortes Suprema de Justicia y de Tribunales Colegiados de igual categoría, y evitar la elección de abogados sujetos a compromisos o intereses particulares.

\section{Referencias}

Constitución Politica de la República de Guatemala. (1985). Guatemala.

Estatuto del Juez Iberoamericano, VI cumbre Iberoamericana de Presidentes de Cortes Supremas y Tribunales Supremos de Justicia, celebrada en Santa Cruz de Tenerife, Canarias, España, los días 23, 24 y 25 de mayo de 2001

Ley de Comisiones de Postulación, Decreto número 19-2009 del Congreso de la República de Guatemala.

Ley de la Carrera Judicial, Decreto número 32-2016 del Congreso de la República de Guatemala.

Malem Seña, Jorge F. “Los Jueces: ideología, política y vida privada”. Editorial Tirant lo Blanch. Primera edición. México. 2017. 


\section{Sobre la autora}

\section{Emma Lucrecia García González}

Abogada y Notaria con grado académico de Licenciada en Ciencias Jurídicas y Sociales, egresada de la Universidad de San Carlos de Guatemala, se desempeña como examinadora de Exámenes Técnicos Profesionales área Púbica y Privada de la Universidad de San Carlos de Guatemala tiene pensum cerrado en la Maestría en Derecho Constitucional Facultad de Ciencias Jurídicas y Sociales del Centro Universitario de Oriente.

Copyright (c) Emma Lucrecia García González

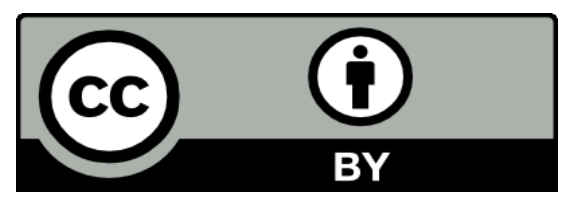

Este texto está protegido por una licencia CreativeCommons 4.0.

Usted es libre para compartir, copiar y redistribuir el material en cualquier medio o formato y adaptar el documento, remezclar, transformar y crear a partir del material para cualquier propósito, incluso comercialmente, siempre que cumpla la condición de atribución: usted debe reconocer el crédito de una obra de manera adecuada, proporcionar un enlace a la licencia, e indicar si se han realizado cambios. Puede hacerlo en cualquier forma razonable, pero no de forma tal que sugiera que tiene el apoyo del licenciante o lo recibe por el uso que hace. 